\title{
A teoria da agenda globalmente estruturada para a educação e sua apropriação pela pesquisa em políticas educacionais
}

\author{
The theory of Globally Structured Agenda for Education and its appropriation \\ by educational policies research \\ La teoría de la Agenda Globalmente Estructurada para la educación y su \\ apropriación en la investigación en políticas educativas
}

ÂNGELO RICARDO DE SOUZA

Resumo: Este trabalho se propõe discutir os elementos principais da teoria da agenda globalmente estruturada para a educação (AGEE), elaborada por Roger Dale (2004), buscando mostrar suas potencialidades e limites para a pesquisa em políticas educacionais. O texto apresenta as contribuições e limites da mencionada teoria, bem como analisa como os pesquisadores brasileiros têm-se apropriado de suas ideias. Ao final, o artigo ainda indica possibilidades de abordagens para a pesquisa em políticas educacionais com base na teoria da AGEE.

Palavras-chave: Agenda Globalmente Estruturada para a Educação; Políticas Educacionais; Epistemologia; Roger Dale.

Abstract: This work aims to discuss the main elements of the theory of Globally Structured Agenda for Education (GSEA) developed by Roger Dale (2004). It aims to show this theory's potential and limits to research on educational policies. The text presents the contributions and limits of that theory, and analyzes how the Brazilian researchers have appropriated its ideas. Finally, the article also indicates possible approaches for research in educational policy based on the theory of GSEA.

Keywords: Globally Structured Agenda for Education; educational policies; epistemology; Roger Dale.

Resumen: Este trabajo tiene como objetivo discutir los principales elementos de la teoría de la Agenda Globalmente Estructurada para la Educación (AGEE) elaborada por Roger Dale (2004), con el objetivo de demostrar sus límites y potenciales a la investigación sobre las políticas educativas. El texto presenta las contribuciones y los límites de esa teoría, y analiza cómo los investigadores brasileños se han apropiado de sus ideas. Por último, el artículo también indica posibilidades para la investigación en la política educativa basada en la teoría de la AGEE.

Palabras clave: Agenda Globalmente Estructurada para la Educación; Políticas Educativas; Epistemología; Roger Dale. 


\section{INTRODUÇÃO}

Este trabalho discute os elementos principais da teoria da agenda globalmente estruturada para a educação (AGEE), elaborada por Roger Dale $(2004)^{1}$, buscando mostrar suas potencialidades e limites para a pesquisa em políticas educacionais. Dale "parte do pressuposto que não é possível descrever e analisar uma política educacional sem compreender a lógica global de um determinado sistema de produção" (MAINARDES; ALFERES, 2014, p. 397); por isso, as noções de globalização e de educação no contexto global são determinantes para a teoria.

Contudo, para articular-se ao pressuposto mencionado e antes de apresentar a teoria da AGEE, o artigo expõe algumas ideias discutidas pelo autor sobre Estado e educação no contexto da globalização. Na sequência, apresenta-se a teoria da AGEE propriamente dita, bem como são indicados alguns limites de seu uso na pesquisa em políticas educacionais.

Por fim, o texto apresenta um levantamento sobre a produção acadêmica brasileira que cita ou utiliza a teoria da AGEE. Esse levantamento tem o objetivo de mostrar como os pesquisadores têm-se apropriado das indicações da teoria na investigação em políticas educacionais.

Metodologicamente, o levantamento foi realizado a partir da leitura e da análise dos artigos publicados em periódicos acadêmicos por autores brasileiros. A busca se deu por meio do Google Acadêmico, cujo descritor foi Agenda Globalmente Estruturada para a Educação, evitando-se menções a outros artigos em língua estrangeira. O retorno do levantamento indicou 260 citações, isto é, esse é o número de trabalhos acadêmicos, de acordo com a ferramenta utilizada, que citam aquela palavra chave. A maioria desses trabalhos foi excluída desse levantamento, por se tratar de autoria de pesquisadores portugueses, os quais, especialmente pela proximidade acadêmica que Dale constituiu com aquele país, têm utilizado em maior proporção a teoria da AGEE do que os autores brasileiros. Também excluímos do levantamento os trabalhos apresentados em eventos, as teses, as dissertações e os livros. Isso, porque esses trabalhos, em parte, não estão disponíveis integralmente na internet, dificultando sua análise. Depois, optou-se pelos artigos publicados em periódicos por se considerar que, além do crivo de avaliação das revistas acadêmicas, estes tendem a ser os que se mostram mais representativos do uso ou da menção à teoria, dados a divulgação e o alcance

1 A teoria foi publicada em inglês em 2000. Em português, a primeira tradução ocorreu em 2001, publicada na Revista Educação, Sociedade e Culturas, de Portugal. A referência aqui ao ano de 2004 se dá pelo fato de que esta é a edição do artigo publicado no Brasil na Revista Educação \& Sociedade.

464 - RBPAE - v. 32, n. 2, p. 463 - 485 mai./ago. 2016 
dos periódicos. E, com isso, avalia-se que tal amostra, que totaliza 19 trabalhos, é demonstrativa do tratamento dado pelos pesquisadores nacionais à matéria.

\section{ESTADO E EDUCAÇÃO NO CONTEXTO DA GLOBALIZAÇÃO}

A globalização constituiu um cenário novo na organização políticoeconômica mundial. Vários são os aspectos característicos desse contexto, mas dois chamam a atenção em especial pelo inusitado: o primeiro tem relação com o fato de que a globalização inclui virtualmente todas as nações do planeta em um processo calcado no modo capitalista de produção, que é, inicialmente, econômico, mas que se estende à política e à cultura. Essa extensão é produto de uma fase do capitalismo, de tentáculos globais e com amplitude crescente e proporcional ao colapso, no final do século passado, da única alternativa real que se apresentou ao capitalismo; em segundo lugar, há uma novidade sem precedentes nesse contexto: o triunfo desse modelo é o triunfo do sistema em si e não de uma nação em particular (DALE, 2004).

Esse quadro complexo coloca os estados nacionais em outra dimensão na definição dos rumos que desejam tomar. Os aspectos típicos da cultura e da história nacional (ou local) perdem espaço para os tópicos da agenda que advém da necessidade de integração global.

Todavia, a perda desse espaço não é uniforme, estandardizada e sem resistências, uma vez que o estado nacional segue forte, ainda que não absoluto, em boa parte das ações sob sua responsabilidade, pois a "maioria, senão todas as decisões sobre o formato e a direção dos sistemas educacionais nacionais continuam sendo tomadas pelos próprios estados" (Idem, 2005, p. 130), mesmo em um contexto em que a globalização tenciona a uma equalização das agendas políticas.

O que parece ocorrer é que, nesse cenário, modifica-se a relação entre o estado e os diversos campos sobre os quais ele próprio atua. Em particular, chama a atenção o fato de que a política parece perder ainda mais espaço para a economia e o local/nacional se mostra fortemente dependente do global. Há uma espécie de tecnificação da política e da gestão (SOUZA, 2007). Ou, de outra forma, "questões políticas são colocadas de lado e substituídas por perguntas sobre os processos de tomada de decisão; a política é reduzida à administração. O foco está na máquina, ao invés de o que a empodera, ou como e onde é conduzida" (DALE, 1989, p. 24). De alguma forma, parece haver alguma contradição na avaliação do poder do estado sobre a definição dos rumos da nação, pois mesmo que o formato e a direção da política, sejam ainda de domínio do próprio estado nacional, há pelo menos dois aspectos que tensionam esse poder. O primeiro tem relação com o 
poder de definir a agenda em torno da qual as decisões são tomadas. Isso porque a definição da agenda, ou seja, sobre o que se tomarão decisões ${ }^{2}$ é algo que, com a globalização, tem progressivamente saltado da esfera nacional para a global. Isso quer sugerir que os estados nacionais tomam decisões sobre a forma e a direção da política, mas pautadas por uma agenda que, se não lhes é imposta, é fortemente influenciada externamente.

O outro aspecto se relaciona com as formas de composição da agenda, o que Dale (2005) denomina regras do jogo, assim como quem pode ou não participar desse processo. Logo, as regras do jogo e o poder de participação dos distintos atores são coisas que escapam ao poder dos estados nacionais. Assim, um estado nacional fica enclausurado entre sua autonomia de definição das políticas, com todo um aparato do estado que lhe é próprio, e a tensão provocada por uma agenda que é dominantemente externa, que lhe apresenta demandas as quais nem sempre são capazes de serem atendidas por seus aparelhos ou não correspondem às demandas locais/nacionais mais imediatas.

E essa agenda tem na economia seu principal motor. Um importante elemento que parece confirmar esta hipótese é a crescente presença da economia do conhecimento (EC - knowledge economy) como referência para a definição de políticas (não apenas educacionais) mundo afora (Idem).

A EC indica que o conhecimento e a educação podem ser equiparados a um produto negociável e, como todo produto ou serviço (educacional ou de inovação intelectual), pode ser negociado, comercializado, exportado com boa taxa de retorno.

Nesse ciclo do capitalismo global, a economia do conhecimento parece mostrar-se como uma mudança qualitativa. Mas a literatura (DALE, 2005; GUILE, 2008) tem destacado que a economia do conhecimento não se apresenta como um discurso uníssono, tanto que a UNESCO, de um lado, a OCDE, de outro, e Banco Mundial, em outro canto, ainda, têm conceitos, leituras e propostas diferentes para o incremento dessa economia.

Um aspecto importante dessa perspectiva é, como antecipado, uma leitura muito técnica da economia e da educação, ao invés de política. A política (educacional) é submetida à direção macro estabelecida pela economia, mas não apenas pela dependência que a política tem dos recursos financeiros, senão que pela própria compreensão de como o Estado (e nele, a política) deve funcionar. Isto é, trata-se de uma definição ideológica acerca de qual é o papel do Estado. O curioso é que a definição da agenda que pauta a política é, ela mesma, uma ação

2 Assim como, sobre o que não se poderão tomar decisões. 
dominantemente política, mas que busca encontrar sempre uma razão técnica (leia-se econômica) para justificar a inclusão de tal ou qual ponto na pauta.

Contudo, não se pode reduzir tudo à economia ou ao modo capitalista de produção ou, ainda, nos tempos atuais, ao sistema global (BECKERT, 2014; STREECK, 2014). Pois, ainda que os "problemas básicos dos sistemas educacionais em países capitalistas derivem dos problemas do Estado Capitalista" (DALE, 1989, p. 25), há pelo menos duas limitações nessa leitura. Antes de tudo, ao mostrar tal associação, pode-se supor que todas as ações do estado têm um grau absoluto de dependência do sistema. Ademais, há um universo de aspectos que ocorre no microuniverso escolar que tem conexão muito distante ou mesmo não tem conexão alguma com os problemas do Estado capitalista.

Isto, porque a educação, como aparato do Estado (Idem) (e sua tradução ou implementação política) são elaboradas cotidianamente não no cumprimento linear de determinações governamentais, mais suscetíveis a terem sido tomadas a partir daquela pauta mencionada, senão que a partir de uma rede complexa de atores, contextos e posicionamentos ${ }^{3}$. O que quer dizer que, enquanto o capitalismo como modo de produção domina muitas formações sociais, sozinho, o modelo não determina a forma que a educação como aparato de estado tomará (Idem, p. 34). O peso da estrutura burocrática, por exemplo, é determinante para a composição e funcionamento deste aparato (SOUZA, 2007; BELLARDO, 2015) e, por vezes, ele é concorrente com o incremento da produtividade apregoado pela EC.

Contudo, o processo de globalização, na sua face cultural, cobra maior homogeneização e rotinização, como o isomorfismo global dos currículos (MEYER et al, 1992). Assim, o que a globalização tem acarretado para os sistemas educacionais são influências não apenas na área dos recursos financeiros, ainda que isso também esteja ocorrendo, mas uma reestruturação da própria noção de educação como aparato do estado (DALE, 1989), cambiando o lugar e a razão educativa:

As mudanças exigidas pela Economia do Conhecimento implicariam a transformação dos sistemas de ensino como os conhecemos; (porém) mesmo a reforma radical destes sistemas seria insuficiente para provocar a mudança de “educação em instituições” para "aprender em qualquer lugar, a qualquer hora e só para mim” (Idem, 2005, p. 118).

3

Em artigo de 2010, Dale revisita os conceitos de Estado e Educação que havia elaborado na pesquisa que se utiliza nesta passagem. Há várias releituras importantes feitas pelo autor, mas não são redefinidoras dos conceitos para os objetivos deste artigo. 
Ainda com essas mudanças, parece que a globalização continua promovendo os objetivos da educação no contexto capitalista, em especial a ideia de manutenção de uma hegemonia não hostil à acumulação capitalista. Mas, ao mesmo tempo, é importante reconhecer que a reprodução econômica e política que continuam presentes na escola, ocorrem em contexto político e cultural particular (Idem).

Na sequência, passamos à análise da Teoria da AGEE, tendo em vista sua potencialidade em auxiliar a compreensão das contradições sinalizadas.

\section{A TEORIA DA AGENDA GLOBALMENTE ESTRUTURADA PARA A EDUCAÇÃO}

A globalização constitui a condição primeira para a compreensão desta teoria, pois é com a emersão de "forças econômicas operando supra e transnacionalmente para romper, ou ultrapassar, as fronteiras nacionais, ao mesmo tempo que reconstroem as relações entre as nações" (Idem, 2004, p. 423), que as influências e impactos da economia na organização da vida política, social e cultural dos povos mudou radicalmente nas últimas décadas. Isso quer dizer que a educação, cada vez mais tratada como uma mercadoria (Idem, 2005), não conseguiria ficar imune à globalização.

Vários estudos têm-se dedicado a confirmar essa relação entre educação e globalização, tanto no espaço central da agenda internacional quanto na periferia dos centros de tomada de decisões. Casassus (2001) e Trojan (2009), por exemplo, mostram leituras conjunturais da educação latino-americana, décadas após o início das reformas educacionais na região. Ambos os autores destacam a tendência predominante em curso na região que mantinham a direção dada às reformas educacionais articulando-as aos acordos firmados entre governos nacionais e as agências internacionais de fomento. E isto, segundo Dale (2004), não é privilégio da América Latina.

Dale (2004) destaca que a globalização tem um conjunto de implicações muito forte sobre a educação e isto não é reduzido a um país em particular, de forma que a estruturação dessa influência se traduz, em essência, a uma espécie de governação global.

Para a teoria da AGEE, o que temos na globalização atual é uma mudança qualitativa no empoderamento capitalista. A economia, como destacado, é a grande chave para a regulação e para a definição das políticas nos níveis nacional e internacional. Mas as instituições e a política educacional não mudam tão rapidamente nessa direção como a economia. Nesse sentido, a teoria aponta a importância de se definirem três elementos, de maneira que isto seria decisivo

468 - RBPAE - v. 32, n. 2, p. 463 - 485 mai./ago. 2016 
para se conhecerem melhor as influências da globalização sobre a política e sobre a educação: (a) especificar a natureza da globalização, (b) indicar claramente o que é que se quer dizer com "educação" e (c) especificar como a globalização afeta a educação (Idem).

O fenômeno global equivale a um conjunto de dispositivos políticoeconômicos para a organização da economia global, conduzido pela necessidade de manter o sistema capitalista, mais do que qualquer outro conjunto de valores. Isso conduziu também à criação de novas formas de governação supranacional que assumiram formas de autoridade sem precedentes por meio das Organizações Internacionais não-Governamentais (OCDE, UNESCO, Banco Mundial). Contudo, elas não operam de maneira tão articulada. Ao contrário, respondem a interesses imediatos, por vezes contraditórios ou não coincidentes. Para a UNESCO, por exemplo, todas as pessoas têm direito ao que chamamos no Brasil de Educação Básica (UNESCO, 2000), já para o Banco Mundial, todos devem ter educação focada em habilidades básicas com formação extraescolar conforme o perfil do mercado e da sociedade (BANCO MUNDIAL, 2011). Os custos e consequências disso são diferentes, além do que representam, em termos de direito à cidadania, à cultura e à inserção na sociedade. Todavia, ainda com essas divergências, há uma prevalência na definição do corpus da agenda e essa diretriz geral parece ser mais bem representada, por vezes, por uma dessas instituições, por vezes, por outra, com articulação, mas com um tanto de contradição agenda (DALE, 2004). Isso retira ou minimiza a possibilidade de se supor uma ação articulada ou, pior, conspiratória em favor da imposição de uma agenda sobre a autonomia dos estados.

Para a teoria da AGEE, o que as organizações internacionais definidoras da agenda pontuam é: a) estandardização da educação, o que significa trabalhar com a ideia de que a fixação de normas de desempenho que irão necessariamente melhorar os resultados educacionais, ou seja, implica reduzir a compreensão de educação à noção de altos resultados em testes estandardizados; b) decorrente do ponto anterior, foco nos objetivos centrais, especialmente numeracia e letramento; c) busca por formas de baixo risco para alcançar as metas de aprendizagem, o que representa a definição de um padrão mínimo de financiamento, mas de retorno garantido; d) uso de modelos de gestão empresarial como referências para a melhoria da educação, mas que, segundo Dale (2014), pode limitar o papel das tentativas nacionais no aprimoramento dos sistemas de ensino, porque via de regra paralisa professores e escolas ao adotarem modelos pouco conhecidos; e) adoção de políticas de accountability vinculadas à avaliação de desempenho, o que está conectado com a nova responsabilização docente e institucional. 
Logo, essa agenda consiste dominantemente em processos de padronização da educação, o que parece sinalizar que ela aponta para uma redefinição do que se entende por educação. O que está em questão é, portanto, a própria concepção de educação, simplificada na relação de estabelecimento de um currículo estandardizado focado em matemática e língua materna, com processos padronizados de testagem de resultados, garantidos por uma gestão focada nos resultados, que tensiona a redefinição do trabalho docente, com o suporte de um padrão mínimo de financiamento educacional.

Em relação ao currículo, não parece haver, nem ser possível em curto período, um modelo global, especialmente por conta das especificidades do trabalho docente, que garante, mesmo com dificuldades, alguma autonomia no processo de ensino, o que tem servido, inclusive, como instrumento de resistência a reformas educacionais (CASASSUS, 2001). Contudo, há uma aproximação dos currículos mundo afora, de maneira que eles estão se tornando mais parecidos (MEYER et al, 1992). Trata-se de uma questão muito simbólica, porque é derivada do processo de globalização, mas, ao mesmo tempo, trata-se de uma espécie de neocolonialismo cultural. $\mathrm{O}$ que pode provocar maior aproximação ainda é o surgimento/incremento de mecanismos avaliativos internacionais, como o PIS A, conduzido pela OCDE, que, como boa parte das avaliações externas não se foca no que foi ensinado, mas, sim, em uma régua externa impositiva, que tem crescente poder de indução do que deveria/deverá ser ensinado (FREITAS, 2007).

A incorporação de modelos de gestão empresarial na educação não é algo novo. Na verdade, nos EUA e no Brasil, a própria origem da administração educacional está fortemente vinculada à teoria geral da administração (SOUZA, 2007). O que não impede, de tempos em tempos, que ressurja o conflito entre a escolha de um modelo de gestão mais vinculado à natureza do objeto administrado, nesse caso a educação, versus a incorporação de modelos exógenos. O que a agenda internacional traz é a ênfase na gestão por resultados. Em publicação conjunta da OCDE e Banco Mundial (BANCO MUNDIAL; OCDE, 2015), há explícitas indicações dessa concepção para o desenvolvimento de políticas sociais, ainda que apareça com nova roupagem. Esse modelo de gestão é orientado para os resultados, isto é, focaliza no estabelecimento de resultados mensuráveis a obter no futuro e na posterior definição de procedimentos de ação para atingi-los.

Quanto às carreiras docentes, há estudos desenvolvidos pela OECD $(2013$; 2014) que mostram o roteiro esperado na formação, contratação, regulação e avaliação. O destaque que a organização dá a tais aspectos está articulado à necessidade de se buscarem formas de ampliar a atração à carreira docente. Mas a vinculação direta dessa atração ampliada deve estar posta no incremento de práticas avaliativas sobre o trabalho docente, conectadas a um rol explícito 
de responsabilidades, que modifica o fazer docente como tradicionalmente desempenhado.

Em 2002, a UNESCO já mostrava um quadro preocupante quanto ao financiamento da educação, dado o aumento das faixas de educação compulsória, de um lado, e a pressão por educação superior gratuita (UNESCO, 2002). Por isso, a organização apontava para a necessidade de um patamar mínimo de vinculação orçamentária para com a educação ( $0,7 \%$ do Produto Interno Bruto) (Idem, 2000). Contudo, seja pelas dificuldades de cumprimento dessa meta, seja pela desigualdade econômica internacional, há um déficit anual de 22 bilhões de dólares americanos para se atingir a universalização da pré-escola ao final do Ensino Fundamental (K-9) até o ano de 2030 (Idem, 2015). Uma questão forte, todavia, que se apresenta sobre esse ponto da agenda é: quem custeará esse serviço? Como se trata da educação compulsória, para a UNESCO isso é tarefa dos estados nacionais. Mas, segundo a organização, o impacto para as finanças públicas pode ser diminuído tanto pela constituição de mecanismos colaborativos com o segmento privado, como pela diminuição da tarefa do poder público para com o financiamento da educação secundária e superior.

A AGEE busca, assim, mostrar "como é que uma nova forma de força supranacional afeta os sistemas educativos nacionais" (DALE, 2004, p. 454). Contudo, aquelas contradições apontadas no item anterior, também se mostram aqui, marcando os limites da noção de Agenda Globalmente Estruturada para a Educação no uso da análise da política educacional.

\section{OS LIMITES DA AGEE}

A despeito da teoria da AGEE contribuir para a análise das políticas educacionais, como se evidencia mais adiante, permitindo uma leitura que incorpora elementos que potencializam um quadro mais panorâmico do processo de tomada de decisões na política educacional, há diversos limites que se apresentam nessa teoria. Alguns deles foram indicados pelo próprio autor (DALE, 2004; 2014).

I. A composição da agenda, de fato, nunca foi completamente decifrada.

A teoria mostra evidências que indicam tendências na composição da agenda global para a educação, mas não explicitam o roteiro da agenda. Primeiro, porque a agenda é uma tendência e não uma lista linear e impositiva de pautas. Ademais, a agenda tende a se conformar conforme o contexto no qual atuará. 
De qualquer sorte, a teoria da AGEE apenas indica as grandes referências para a pauta educacional global, com influências sobre as pautas locais/regionais.

II. A leitura que a teoria da AGEE faz da globalização pode sugerir a ideia de que tudo se resume ao neoliberalismo

Isto é, a teoria pode transparecer que pressupõe certa inevitabilidade acerca das influências que a globalização geraria sobre a educação e outros aspectos da vida pública e que tais aspectos adviriam, por natural, da predominância do modelo neoliberal na condução política e econômica dos estados nacionais (MUNDY, 2007). Assim, o analista de políticas educacionais pode ser levado a tal equívoco, pela conexão que a teoria sugere a partir da amplitude da globalização e do neoliberalismo sobre as diversas faces da vida e das organizações societárias.

\section{Certa imposição teórico-metodológica}

Esse limite se articula ao anterior, pois o analista, utilizando os referenciais dessa teoria, se os tomar isoladamente pode correr o risco de produzir uma "análise míope" (DALE, 2014) da realidade, uma vez que pode vir a tomar o neoliberalismo como fornecedor das suas próprias condições de existência. Vale dizer, como a teoria trabalha com a leitura da estrutura capitalista na base explicativa dos fenômenos da política educacional, qualquer análise depende, necessariamente, da compreensão e aceitação de seus pressupostos de economia política.

IV. Importância subestimada de desenvolvimentos regionais

A teoria da AGEE pode dificultar a leitura local/regional, se o analista deixar de compreender que os arranjos locais/regionais têm, em alguma proporção, influência sobre as formas e direções dadas à política educacional. $\mathrm{O}$ que significa que, mesmo com a influência marcante da AGEE, há movimentos dos sujeitos que operam a disputa na política local/regional, que resistem, bloqueiam, redirecionam ou desconsideram aquela influência.

Mas, mesmo assim, também é preciso compreender que os desenvolvimentos regionais também estão articulados, dominantemente, à lógica do capital. Isto é, o que fazemos em termos de política educacional no Brasil, ou na América do Sul, ainda que vinculado ao contexto local/regional e, portanto, 
típico, trata-se de decisões tomadas no contexto do capitalismo, em sua fase globalizada.

V. Assunção enganosa de homogeneidade

$\mathrm{O}$ analista pode ser levado a não perceber a heterogeneidade das diferentes frações do capital, assim como, a não perceber ou diminuir as disputas entre capital e trabalho e suas decorrências sobre a definição de políticas educacionais. Dale (Idem) afirma que a AGEE poderia ser vista como uma espécie de mínimo denominador comum de interesses compartilhados pelo capitalismo, ao invés do que os de qualquer fração particular, mas ela é sempre afetada por lutas entre esses grupos, posto que para a teoria é o próprio sistema capitalista que impulsiona essa agenda, e não cada país isoladamente.

VI. A modernidade ocidental é tomada como referência tanto teórica quanto normativamente

O foco é a natureza dos valores da modernidade ocidental, mas isso parece advir do próprio fato de a globalização ter o seu berço e difusão no capitalismo ocidental moderno. Contudo, mesmo com certa tendência à ocidentalização da política, a teoria poderia indicar explicações que não são suficientes em especial em países orientais.

\section{Outros fatores}

Há um conjunto de outros aspectos que a AGEE ignora ou minimiza como preponderantes na definição de políticas educacionais, que estão associados à religião, aos conflitos bélicos e às tradições, os quais, dada sua força histórica ou local, podem mostrar-se predominantes diante da agenda global.

Esses limites, todavia, não invalidam a teoria. Ao contrário, tensionam os analistas a compreender até qual ponto podem utilizá-la, ou quais conclusões podem ser endereçadas à AGEE.

A pesquisa em políticas educacionais no Brasil tem tomado essas contribuições ao longo dos últimos dez anos. O próximo item trata da análise desta produção, buscando evidenciar como a teoria tem sido utilizada, bem como suas potencialidades para os pesquisadores brasileiros. 


\section{A APROPRIAÇÃO DA TEORIA DA AGEE PELA PESQUISA EM POLÍTICAS EDUCACIONAIS NO BRASIL}

Separamos os trabalhos analisados em duas categorias, como pode ser observado no quadro mais abaixo: aqueles que citam a teoria da AGEE e aqueles que a utilizam para análise do seu objeto próprio de pesquisa.

Dentre os trabalhos que apenas citam a AGEE, o primeiro deles, em ordem cronológica, é o artigo de Sampaio e Marin (2004), cujo foco é a discussão sobre a precarização do trabalho docente, em leitura cotejada com as práticas curriculares. As autoras citam a teoria como contexto explicativo, isto é, como instrumento para compreensão das relações entre a manutenção do sistema capitalista, as mudanças na economia mundial e as alterações na política educacional que incidem sobre o objeto por elas estudado.

Seguindo a ordem cronológica, temos o trabalho de Oliveira (2005), que discute a regulação das políticas educacionais e suas conexões com o trabalho docente. A pesquisadora toma a leitura que Dale faz da relação entre globalização e educação, procurando analisar o contexto daquela regulação nos marcos da globalização. O trabalho chama a atenção para o elemento diferencial da teoria da AGEE, destacando que esta perspectiva não trata, como outras teorias, de observar as relações entre educação e globalização "como um reflexo da cultura ocidental, baseada cognitivamente em torno de um conjunto particular de valores que penetram em todas as regiões da vida moderna" (p. 761). De qualquer maneira, a AGEE também aparece nese artigo mais como contexto.

O trabalho de Oliveira (2007) analisa o acesso aos ensinos fundamental e médio no Brasil, buscando discutir a questão da qualidade como condição do direito à educação no país. O autor, dentre outros aspectos, critica leituras reducionistas acerca das reformas educacionais, as quais tiveram papel preponderante na ampliação do acesso à Educação Básica. Aqui entra a referência à AGEE, que é criticada por ser utilizada como elemento explicativo em demasia por pesquisadores do campo. Isto é, o autor sugere que a teoria da agenda tem sido utilizada para explicar o que ela não pode explicar, por exemplo, as diferenciações no desenvolvimento e implantação de reformas educacionais em diferentes países, os quais, sabidamente, não têm respostas idênticas mesmo que diante de problemas semelhantes.

O trabalho de Mari (2008) é o próximo dentre aqueles que citam a AGEE. Esse artigo tem por objeto a sociedade do conhecimento. $\mathrm{O}$ autor discute quão ideológica é essa concepção e busca evidenciar como ela é produto da ampliação das relações entre a ciência e os interesses do capital. A AGEE se apresenta 
como explicação para o papel ideológico que os organismos internacionais desempenham na edificação da concepção.

O artigo de Lima e Contel (2008) discute as políticas de internacionalização da Educação Superior no Brasil. O trabalho dos autores é derivado de um levantamento feito com o intuito de compreender melhor o sentido que as instituições de Educação Superior brasileiras dão à internacionalização da educação, assim como o grau de institucionalidade que as IES conferem à política de internacionalização. O estudo apenas menciona a AGEE como cenário explicativo de um ponto em particular que surgiu durante a pesquisa, que é a questão da mercantilização da educação.

O texto de Evangelista (2008) trata das Diretrizes Curriculares Nacionais para o curso de pedagogia, com o foco de análise sobre as relações que se constituem entre a formação para a docência e o papel da pesquisa nesse processo. A teoria da AGEE é convidada a esse artigo também em caráter de contextualização. A autora a cita para confirmar a existência de uma agenda que deixa muitos estados nacionais submissos a políticas internacionais, contexto esse em que se observa a divisão entre países produtores e os consumidores de conhecimento. O debate que interessa à autora é a crítica a dadas concepções mais instrumentalistas e utilitárias da educação, para as quais a AGEE é chamada como elemento explicativo.

Ainda em 2008, temos o artigo de Adrião e Garcia, cujo foco é a análise das noções de responsabilização no Plano de Desenvolvimento da Educação. As autoras consideram o contexto de reforma do estado e das políticas de descentralização na oferta educacional. Por essa razão, a AGEE é convocada na condição de explicação de contexto e, segundo as autoras, a agenda é emersa das conferências da UNESCO de 1990 (Jomtien) e 2000 (Dakar).

Em 2009, temos o artigo de autoria de Campos e Campos, que estudam o Programa Família Brasileira Fortalecida para o atendimento de crianças de 0-3 anos de idade. As autoras mostram que o programa se constitui como peça da política educacional que não pode ser compreendida isoladamente, uma vez que "mantém estreita vinculação com programas semelhantes desenvolvidos em outros países da região, podendo ser compreendido como expressão local da agenda global" (CAMPOS; CAMPOS, 2009, p. 215).

O artigo de Chapani et al (2010) toma a regulação da formação docente para analisar o posicionamento dos docentes em um contexto de mudanças no mundo do trabalho e da cultura. Os autores buscam discutir essa temática frente à teoria social de J. Habermas. A AGEE é apenas mencionada para explicar em qual contexto aquelas mudanças ocorrem. 
O trabalho de Aguiar (2010) toma a teoria do Capital Humano como objeto de estudo, identificando-a como uma produção do século XX que ainda perdura, tendo em vista a lógica economicista que tende a ser apresentada como justificativa para as políticas educacionais. O trabalho busca a AGEE para mostrar que as reformas educacionais que ocorreram no Brasil e em outros países são constituidoras de uma nova governabilidade dos sistemas educacionais, voltada a objetivos que pouco se aproximam de questões educativas propriamente ditas, ficando mais restritas a escopos econômicos.

Bianchetti (2011) é autor do próximo artigo que cita a AGEE. Nesse texto, o autor discute as condições de trabalho na pós-graduação brasileira. O autor critica o fato de que, mesmo o sistema de pós-graduação no Brasil sendo alvo constante de reclamações pelos docentes e pesquisadores, não parece haver movimentos fortes contra ele; ao contrário, parece ocorrer uma naturalização e incorporação dos princípios organizacionais do sistema. O trabalho mostra que o sistema de pós-graduação brasileiro passou a ser uma política de estado, mas essa política indica o quanto o Brasil está avançando rumo à AGEE, pois “não há como ignorar uma série de decorrências negativas ou subprodutos, induzindo a atitudes e posturas que são tomadas frente à escolha por estar incluído no sistema ou os preços pagos por estar fora" (p. 444).

O trabalho de Jezine et al (2011) é uma comparação de elementos de política educacional de Portugal e Brasil, na qual os autores observam condições de acesso ao ensino superior em ambos os países, buscando mostrar convergências e divergências. O artigo cita a AGEE para explicar o contexto da globalização, no qual as políticas de acesso ao ensino superior têm sido remodeladas.

O artigo de Goergen (2012) também focaliza a Educação Superior. Seu objeto, todavia, são os programas de pós-graduação no Brasil, em um contexto de "planetarização, globalização e internacionalização" (p. 247). A teoria da AGEE ganha um pouco mais de espaço do que o usual dos trabalhos que apenas a citam. Mesmo não sendo convocada para análise dos dados da pesquisa, a teoria é lembrada para contrapor o argumento de que os sistemas educacionais são organizados autonomamente pelos estados nacionais e para mostrar que as diferenças entre os países, e entre suas políticas educacionais, tendem a se reduzir com o passar do tempo.

Por fim, o trabalho de Carvalho (2014), que se apresenta como um estudo comparado das reformas ocorridas na administração da educação no Brasil e em Portugal, focalizando as razões da relativa homogeneidade do novo modelo de gestão escolar e a identificação das orientações comuns e das particularidades dos modos de apropriação de tal modelo nos dois países. A autora convida a teoria da 
AGEE para identificar os efeitos dos processos da globalização na constituição de uma agenda global para as reformas da educação de ambos os países.

De outro lado, temos os trabalhos que tomam a teoria da AGEE como base para a análise na pesquisa desenvolvida. O primeiro desses trabalhos, também cronologicamente, é o artigo de Shiroma e Evangelista (2004), que coloca em foco dois importante temas: a profissionalização docente e a gestão da educação. As autoras discutem esses temas à luz de várias contribuições, mas utilizam a AGEE como um importante referencial na direção de avaliar que a profissionalização docente não pode ser concebida de maneira linear e não diferenciadora, considerando o cenário internacional. Desse modo, se o projeto de profissionalização docente pode trazer elementos em comum ou incluir funções assemelhadas, em diferentes regiões do mundo, há elementos locais que precisam ser considerados, ainda que sob a pressão derivada da agenda global, que tenciona pela incorporação de padrões internacionais às reformas do trabalho docente.

Em 2006, temos outro artigo de autoria de Shiroma e Evangelista, que analisam o surgimento de um novo tópico na agenda global, que é a educação para o alívio da pobreza. As autoras mostram, utilizando a AGEE, como cambiou o uso de termos como produtividade, qualidade, eficiência e eficácia para inclusão, coesão social, empowerment e oportunidade, entre os anos 1990 e a primeira década do século XXI. As autoras analisaram documentos dos organismos internacionais e flagram esta mudança de agenda, à qual atribuem um redirecionamento do discurso conduzido por esses organismos com vistas a reequilibrar conflitos decorrentes da extrema pobreza.

O artigo de Scocuglia (2008) analisa as influências e respostas da política educacional brasileira diante do cenário internacional. $\mathrm{O}$ autor trabalha com a ideia de Souza Santos de "globalizações", e coteja esse conceito com a teoria da AGEE. O autor apresenta as principais ideias da teoria e as coloca em ação na leitura de peças da política educacional nacional. Ao concluir, o trabalho encontra elementos importantes na política educacional brasileira conectados com a disseminação de traços da AGEE.

Campos (2009), em seu artigo sobre projetos e programas para a educação infantil na América Latina, analisa três iniciativas políticas, referenciando a pesquisa no trabalho de Dale sobre a AGEE. O trabalho toma a teoria para compreender o conceito de globalização; para analisar as políticas educacionais nacionais em um quadro mais amplo; para considerar que as intercorrências da globalização sobre a educação provocam efeitos diferenciados e, finalmente, para compreender que a regulação dos sistemas educacionais tem tendido a responder a uma agenda global. Nas conclusões, a autora aponta que "é importante compreender a atenção destinada à Educação Infantil não como um movimento isolado, mas 
parte constituinte de indicações mais amplas destinadas a orientar os países na reforma dos seus sistemas educacionais" (CAMPOS, 2009, p. 36).

Nesse segundo grupo de artigos, ainda temos dois últimos trabalhos que tratam da teoria da AGEE, mas que não a utilizam para analisar dados de pesquisa, senão que analisam a própria teoria. Isto é, são trabalhos de avaliação da produção acadêmica desenvolvidos em um esforço recente da área que tem buscado constituir redes de investigação sobre a produção teórica no campo. $\mathrm{O}$ primeiro desses trabalhos é de autoria de Tello e Mainardes (2012), que descreve e analisa as perspectivas epistemológicas utilizadas em pesquisas sobre política educacional na América Latina. Tomando artigos entre 1993 e 2001, o trabalho percebe a presença de referências teóricas de autores que eles denominam pesquisador-referente. É nesse contexto que Dale e a teoria AGEE são apresentados e são evidenciados como fonte importante na região. A pesquisa mostra, todavia, que, seja acerca da teoria da AGEE, seja com outras perspectivas teóricas, percebese um uso de "referenciais teóricos colocados em termos de metodologia, sem levar em consideração as bases epistemológicas para a qual foram produzidos" (TELLO; MAINARDES, 2012, pp. 24-25).

O último trabalho que aqui analisamos é de autoria também de Mainardes \& Alferes (2014). O foco do trabalho dos autores é apresentar um levantamento do conceito de sociologia das políticas educacionais, articulando a isto as ideias desenvolvidas por Dale. O artigo não foca somente a teoria AGEE, pois toma a obra de Dale de maneira mais ampla, mas apresenta uma boa revisão sobre a teoria e mostra potenciais usos das contribuições de Dale para a pesquisa do campo, concluindo que tais ideias "são abrangentes e complexas e oferecem contribuições extremamente ricas para a pesquisa de políticas educacionais, em uma perspectiva crítica" (2014, p. 411).

A leitura mais ampla de todo esse material indica que os trabalhos que fazem menção à AGEE tendem normalmente a uma indicação superficial da teoria, como se a simples menção fosse suficiente para identificar o contexto no qual se circunscrevem os objetos pesquisados. Isto é, quando a AGEE é apresentada como justificativa de contexto, os trabalhos tendem a tratar dela superficialmente, como é o caso de Sampaio e Marin (2004), Adrião e Garcia (2008), Campos e Campos (2009), Chapani et al (2010) e Bianchetti (2011).

Ocorre algo parecido com os artigos que tomam a AGEE para utilizar o conceito de globalização (OLIVEIRA, 2005; JEZINE et al, 2011). Como não se trata de algo estático, de acordo com a teoria, a falta de menção a essa característica do fenômeno fragiliza alguns artigos.

De outro lado, os trabalhos que buscam relacionar local e global (LIMA; CONTEL, 2008; GOERGEN, 2012), assim como os que utilizam a teoria para 
contribuir para os conceitos de educação (EVANGELISTA, 2008) e acerca das influências dos organismos internacionais (MARI, 2008) tendem a mostrar uma apropriação interessante da teoria, demonstrando reconhecer os limites do uso da noção de agenda para interpretar a pauta e os processos influenciadores na elaboração das políticas educacionais. Há, contudo, em especial para os artigos que relacionam o local e o global, alguma linearidade nas análises, o que precisa ser corrigido com estudos que percebam mais complexamente o problema.

Os artigos, com uma única exceção, não mostram, contudo, uma leitura crítica à teoria AGEE. Apenas o texto de Oliveira (2007) indica claramente os limites da teoria, quando critica o uso da noção de agenda como elemento explicativo da política. Contudo, parece-nos que o autor, mesmo tendo apresentado um ponto interessante (o de que as pesquisas no Brasil tendem a simplificar a noção de elaboração de políticas), parece não ter compreendido que a teoria da AGEE não deslegitima ou desconhece o espaço local ou nacional ou as contradições nos processos de tomada de decisões, pois o foco da teoria incide justamente sobre as influências globais. De qualquer forma, chama a atenção que, afora esse, os demais trabalhos não tenham tomado a teoria como hipótese (BRANDÃO, 1992), senão como explicação contextual ou causal dos fenômenos estudados.

São os artigos que trabalham com a teoria os que parecem produzir melhor e apropriada análise da AGEE. Mas, mesmo aqui encontramos artigos (SCOCUGLIA, 2008; CAMPOS, 2009) que fazem uso insuficiente da teoria que anunciam nas conclusões dos seus artigos.

A teoria da AGEE não tem a condição explicativa definitiva sobre a elaboração de políticas educacionais; de resto, porque nenhuma teoria terá esta condição, dada a dinamicidade das políticas e dos contextos e a sempre presente possibilidade de serem analisadas de distintos lugares e olhares. De qualquer sorte, a teoria tem um potencial de contribuição interessante para a pesquisa do campo no Brasil. Não encontramos, e isto parece estranho, estudos que articulem essa teoria com a pesquisa em planejamento educacional nacional, a qual tem profunda conexão com a noção de agenda.

A noção de agenda também é importante para a pesquisa sobre os processos de tomada de decisões, por exemplo, no parlamento. Assim, pesquisas que tematizem as formas como a normatização educacional é elaborada podem valer-se das contribuições da AGEE.

Em outra dimensão, conforme Mainardes e Alferes (2014), a "relação entre globalização e educação, assim como os efeitos da globalização sobre a educação, bem como o papel do Estado na definição das políticas educacionais" (p. 412), é algo que, mesmo estando presente no levantamento realizado, ainda é temática que pode ser mais bem explorada, em particular porque, como 
mencionado, o contexto tem cambiado com velocidade elevada, provocando os pesquisadores a atualizarem suas análises e conclusões.

Decorrente dessa conclusão, a pesquisa sobre a mercantilização da educação, especialmente no nível superior, pode ter na AGEE um forte aliado, pois as origens e as razões que têm movido as Organizações Internacionais NãoGovernamentais - OING e as empresas transnacionais a operarem nesse mercado, é algo tratado pela teoria.

Por fim, uma última contribuição a ser considerada é a ampliação dos estudos sobre a relação local-global. Há estudos nessa direção, como vimos, mas, por vezes, são estudos que demandam leituras mais aprofundadas que considerem os conflitos e contradições das relações de influência, dependência e resistência da/face à AGEE.

\section{CONCLUSÕES}

Neste trabalho, a teoria da agenda globalmente estruturada para a educação foi colocada em análise, com o intuito de se evidenciarem aspectos que possam contribuir para a pesquisa em política educacional no Brasil. Destacouse, ao final, a produção acadêmica nacional que cita ou toma essa teoria como referência. Os limites, tanto da teoria quanto da pesquisa do campo, também foram indicados ao longo do texto.

A teoria da AGEE nos mostra que a globalização, "na medida em que pode afetar as políticas e as práticas educativas nacionais, implica a apreciação da natureza e da força do efeito extra nacional" (DALE, 2004, p. 425), sem contudo ignorar as forças e resistências intranacionais. Esse parece ser um ponto muito importante neste debate, pois a pesquisa do campo não parece tomar esta teoria com tal apreciação.

Logo, o olhar do analista pode desenvolver-se com mais profundidade nessa direção, observando a influência e os impactos da globalização na organização da educação nacional, sem o determinismo simplificador, que aponta para a existência de uma cartilha, ao invés de uma agenda.

Tem-se a sensação, por vezes, que a pesquisa em políticas educacionais busca mostrar como a educação brasileira é suscetível ou determinada externamente, e vários dos trabalhos que tomam ou citam a AGEE corroboram essa direção. Nesse contexto não nos restaria muito que fazer, pois se as agências internacionais controladoras da agenda são as responsáveis pela determinação da política nacional, por que interessaria conhecer a política educacional de um dado país? Contudo, o que parece necessário se buscar são as influências na composição da agenda e os desdobramentos dessa agenda na realidade educacional nacional, 
o que representa uma leitura mais complexa de aspectos mais contraditórios. Afinal, se a agenda que pauta a política educacional é o primeiro foco de disputa política, ela não é o único e, nas distintas fases da disputa pelo poder na política educacional, a agenda também é tensionada, podendo ser ressignificada.

\section{REFERÊNCIAS}

ADRIÃO, T.; GARCIA, T. Oferta educativa e responsabilização no PDE: o Plano de Ações Articuladas. Cadernos de Pesquisa, v. 38, n. 135, p. 779-796, set./dez. 2008.

AGUIAR, L. C. Um legado do século XX para a política educacional do século XXI: a teoria do capital humano. Revista HISTEDBR On-line, Campinas, n.40, p. 126-144, dez.2010.

BANCO MUNDIAL. Estratégia 2020 para a Educação do Grupo Banco Mundial Resumo Executivo. Washington: Banco Mundial, 2011. Disponível em língua portuguesa em <http:// siteresources.worldbank.org/EDUCATION/ Resources / ESSU/463292-1306181142935/Portguese_Exec_Summary_ ESS2020_FINAL.pdf>. Acesso em março de 2015.

BANCO MUNDIAL; OCDE. Emerging good practice in managing for development results. Disponível em<http://www.oecd.org/development/ effectiveness/36853468.pdf> .Acesso em março de 2015.

BECKERT, J. Capitalist Dynamics: Fictional Expectations and the Openness of the Future. Max Planck Institute for the Study of Societies, Cologne. 2014.

BELLARDO, W. Trajetória da burocracia educacional: recrutamento e recursos de poder.Tese de Doutorado (Educação). Curitiba: UFPR, 2015.

BIANCHETTI, L. Condições de trabalho e repercussões pessoais e profissionais dos envolvidos com a pós-graduação stricto sensu: balanço e perspectivas. Linhas Críticas, v. 17, n. 34, Set-Dez, p. 439-460, 2011.

BRANDÃO, Z. A teoria como hipótese. Teoria \& Educação, n5 5, pp. 161-169, 1992. 
CAMPOS, R. A educação das crianças pequenas como estratégia para a contenção da pobreza: análise de iniciativas dos organismos internacionais em curso na América Latina. Práxis Educativa, Ponta Grossa, v.4, n.1, p.29-39, jan.-jun. 2009

CAMPOS, R.; CAMPOS, R. F. A educação das famílias pobres como estratégia política para o atendimento das crianças de 0-3 anos: uma análise do Programa Família Brasileira Fortalecida. Pro-Posições, Campinas, v. 20, n. 1 (58), p. 207224, jan./abr. 2009.

CARVALHO, E. J. G. Reformas na administração educacional: Uma análise comparada entre Brasil e Portugal. Revista Portuguesa de Educação, 27(1), pp. 29-54, 2014.

CASASSUS, J. A reforma educacional na América Latina no contexto de globalização. Cadernos de Pesquisa. Novembro de 2001, n. 114, pp. 07-28.

CHAPANI, D. T.; CARVALHO, L. M. O.; TEODORO, A. Políticas de formação docente na Bahia: Uma análise a partir de pressupostos da teoria social de Habermas. Revista Brasileira de Pesquisa Sobre Formação de Professores, v. 02, n. 03, p. 66-85, ago-dez. 2010.

DALE, R. Poder, Política e Políticas Educacionais. Universidade Federal de Santa Catarina, 29 de outubro de 2014. Conferência de Encerramento do X Seminário de Pesquisa em Educação da Região Sul. Florianópolis, 2014.

A sociologia da educação e o Estado após a globalização. Educação e Sociedade, Campinas, v.31, n.113, p.1099-1120, out./dez., 2010.

- Globalization, knowledge economy and comparative education. Comparative Education. V. 41, n. 2. P. 117-149, maio de 2005.

Globalização e educação: demonstrando a existência de uma "Cultura Educacional Mundial Comum " ou localizando uma "Agenda Globalmente Estruturada para a Educação"?. Educação e Sociedade, Campinas, vol. 25, n. 87, p. 423-460, maio/ago. 2004.

. The state and education policy. Buckingham, Englad: Open University Press, 1989.

482 - RBPAE - v. 32, n. 2, p. 463 - 485 mai./ago. 2016 
EVANGELISTA, O. Conhecimento e Diretrizes curriculares para o curso de Pedagogia no Brasil. Perspectiva, Florianópolis, v. 26, n. 2, 551-570, jul./dez. 2008

FREITAS, D. N. T. A avaliação da educação básica no Brasil. Campinas: Autores Associados, 2007.

GOERGEN, P. A internacionalização dos programas de pós-graduação. REP

- Revista Espaço Pedagógico, v. 19, n. 2, Passo Fundo, p. 247-257, jul./dez. 2012.

GUILE, D. O que distingue a economia do conhecimento? Implicações para a educação. Cadernos de Pesquisa. V. 38, n. 135, set/dez 2008, p. 611-636.

INSTITUTE FOR INTERNATIONAL EDUCATION - IIE. Open doors 2011: InternationalStudentEnrollmentIncreasedby 5 percent in 2010/2011. Disponível em <http://www.iie.org/en/Who-We-Are/News-and-Events/PressCenter/Press-Releases/2011/2011-11-14-Open-Doors-International-Students>, Acesso em março de 2015.

JEZINE, E.; CHAVES, V.L.J.; CABRITO, B.G. O acesso ao ensino superior no contexto da globalização: os casos do Brasil e de Portugal. Revista Lusófona de Educação, n.18, pp. 57-79. 2011

LIMA, M. C.; CONTEL. F. B. Características atuais das políticas de internacionalização das instituições de educação superior no Brasil. Revista E-Curriculum, São Paulo, v. 3, n. 2, p. 1-25, junho de 2008.

MAINARDES, J.; ALFERES, M. Sociologia das políticas educacionais: contribuições de Roger Dale. Atos de pesquisa em educação. Blumenau, v. 9, n. 2, p. 392-416, mai./ago. 2014.

MARI, C. L. Sociedade do conhecimento: ideologia acerca da ressignificação do conhecimento. Perspectiva, Florianópolis, v. 26, n. 2, 619-638, jul./dez. 2008.

MEYER, J.W.; KAMENS, D.H. Conclusion: accounting for a world curriculum. In: MEYER, J.W.; KAMENS, D.H.; BENAVOT, A. (Org.). School knowledge for the masses: world models curricular categories in the twentieth century. Londres: Falmer, 1992. p. 165-179. 
MUNDY, K. Global Governance, Educational Change. Comparative Education. Vol. 43(3), pp. 39-58. 2007.

OECD. Teachers for the 21st Century: Using Evaluation to Improve Teaching. OECD Publishing, Paris, 2013.

. Education at a Glance 2014: OECD Indicators, Paris; OECD Publishing, 2014.

OLIVEIRA, D. A. Regulação das políticas educacionais na América Latina e suas consequências para os trabalhadores docentes. Educação e Sociedade, Campinas, vol. 26, n. 92, p. 753-775, Especial - Out. 2005.

OLIVEIRA, R. P. Da universalização do ensino fundamental ao desafio da qualidade: uma análise histórica. Educação e Sociedade, vol.28, n.100, pp. 661690. 2007.

SAMPAIO, M. M.; MARIN, A. J. Precarização do trabalho docente e seus efeitos sobre as práticas curriculares. Educação e Sociedade, Campinas, vol. 25, n. 89, p. 1203-1225, Set./Dez. 2004.

SCOCUGLIA, A. C. Globalizações, Política Educacional e Pedagogia ContraHegemônica. Revista Iberoamericana de Educación. n. ${ }^{\circ}$ 48, pp. 35-51, 2008.

SHIROMA, E. O.; EVANGELISTA, O. A colonização da utopia nos discursos sobre profissionalização docente. Perspectiva, Florianópolis, v. 22, n. 02, p. 525 545, jul./dez. 2004.

; _ـ Educação para o alívio da pobreza: novo tópico na agenda global. Revista de Educação PUC-Campinas, Campinas, n. 20, p. 43-54, junho de 2006.

SOUZA, A. R. Perfil da Gestão Escolar no Brasil. Tese de Doutorado (Educação: História, Política, Sociedade). São Paulo: PUC-SP, 2007.

STREECK, W. How will capitalism end? New Left Review. V. 87, May-June 2014.

484 - RBPAE - v. 32, n. 2, p. 463 - 485 mai./ago. 2016 
TELLO, C.; MAINARDES, J. La posición epistemologica de los investigadores en política educativa: debates teóricos en torno a las perspectivas neomarxista, pluralista y pos-estructuralista. Archivos Analíticos de Políticas Educativas, v. 20, n. 9, p. 1-27, mar. 2012.

TROJAN, R. Políticas educacionais na América Latina: tendências em curso. Revista Iberoamericana de la Educación, n. ${ }^{\circ}$ 51/1 - 15 de diciembre de 2009.

UNESCO. Financing Education - Investments and Returns, Analysis of the World Education Indicators, 2002 Edition - Executive Summary. Paris, 2002.

. Final Report, World Education Forum, Dakar, Senegal, 26-28 April 2000, UNESCO, 2000.

Pricing the right to education: The cost of reaching new targets by 2030. Paris, 2015. Disponível em <http://unesdoc.unesco.org/ images/0023/002321/232197E.pdf>. Acesso em março de 2015.

ÂNGELO RICARDO DE SOUZA é doutor em Educação (PUC-SP). Professor associado e pesquisador do Núcleo de Políticas Educacionais (NuPE) e do Programa de Pós-Graduação em Educação (PPGE) da Universidade Federal do Paraná (UFPR). E-mail: angelo@ufpr.br 